\title{
Book Review Section
}

\author{
Letter from the Book Review Editor, KRISTOPHER WELLS
}

Welcome to the inaugural issue of Complicity. We are pleased to include a wide variety of book reviews as an integral part of the journal. We invite researchers, graduate students, practitioners, and independent scholars to submit critical book reviews, suggest potential books for review and develop ideas for clusters of review topics, which may include a selection of related journal articles or a series of books that engage a similar theme or analysis.

Book reviews are designed to provide a quick, informative, and insightful service to Complicity readers. They bring attention to significant publications and trends in the field that the reader may wish to utilize in their research and teaching engagements or add to their own personal libraries. Therefore, the reviewer plays an important role in becoming a part of an unfolding dialogue that shapes the field of complexity and education. Critical reviewers are cognizant of how books and authors can reinforce dominant modes of thinking or prompt new directions for inquiry. As a result, the goals of Complicity book reviews are to challenge boundaries as they question under developed positionings and, in turn promote promising and engaging practices that help to expand emergent understandings of complexivist principles.

Complicity book reviews are relatively brief, approximately 1000-1500 words. Each critical review is crafted with several orienting tasks in mind: (1) assesses and conveys the content and contribution of the book to the field of complexity and education, (2) provides for a critical assessment of the quality and usefulness of the book for educational researchers and practitioners, and (3) seeks to make a scholarly contribution to discourses within the emerging field of complexity and education.

As an international journal we strongly encourage submissions from educators and researchers outside of North America. A selection of books currently available for review can be found on the Complexity and Education website (http: / / www.complexityandeducation.ca)—look under publications for details. In addition to the books listed, we invite readers to suggest other texts that should be considered for review. We look forward to and actively invite your participation in this unfolding dialogue. 